\title{
Ecología de enfermedades infecciosas emergentes y conservación de especies silvestres
}

\author{
Ecology of emerging infectious diseases and wild species conservation \\ G Medina-Vogel ${ }^{*}$ \\ Escuela de Medicina Veterinaria, Universidad Andrés Bello, Santiago, Chile.
}

\begin{abstract}
SUMMARY
Recent literature on emerging infectious diseases in wild species raises international concerns about ocean, terrestrial and freshwater ecosystem health. Reports documenting infectious diseases in wild species from the last 25 years were investigated. The goals of the study were to: 1) assess the importance of habitat and alien species introduction, within the context of pollution and weather change, on emerging infectious diseases, and 2) evaluate the risk of extinction for species of conservation concern. Assessment of several important cases reveals that pathogens responsible for infectious diseases in wild species can be readily transmitted between hosts, leading to short-term epizootic infections that can threaten vulnerable declining populations. Habitat destruction and the introduction of alien species were identified as significant environmental variables that affect the ecology of emerging infectious diseases, while pollution and weather change were found to favor transmission and the creation of new hosts. A transdisciplinary approach is required to confront the multi-causal origin of these diseases. The growing risk of epizootics caused by habitat destruction, pollution and invasive alien species reveals the importance of considering infectious disease ecology in our wild species conservation efforts.
\end{abstract}

Palabras clave: riesgo, enfermedades infecciosas, conservación, especies silvestres.

Key words: risk, infectious diseases, wild species, conservation.

\section{INTRODUCCIÓN}

En la última década varias epidemias han causado dramáticas reducciones de poblaciones de especies silvestres en varias regiones de nuestro planeta como, por ejemplo, distemper en focas, parvovirus en leones, micosis en anfibios, tuberculosis en mustélidos, repentinas muertes de mamíferos, aves y tortugas marinas o terrestres (Daszak y Cunningham 2002). El aumento en la actividad humana, como resultado del incremento de la población y su distribución hacia regiones antes desocupadas con cambios importantes en el uso de las tierras, ha aumentado el contacto entre personas, animales domésticos y silvestres, acrecentando el riesgo de transmisión de enfermedades ya conocidas y el surgimiento de nuevas (eg. ébola, ántrax, influenza aviar, HIV y SARS) (Harvell y col 1999, Daszak y Cunningham 2002). Esta situación ha incrementado en las últimas décadas el riesgo de extinción de especies con problemas de conservación (Haydon y col 2002). Las enfermedades infecciosas emergentes son todas aquellas enfermedades causadas por nuevos patógenos, o patógenos que recientemente han aumentado su incidencia, distribución geográfica, incorporando huéspedes nuevos o recientemente descubiertos (Daszak y col 2000). Esta amplia definición incluye una variedad de enfermedades humanas, pandemias como el sida y patógenos que han desarrollado resistencia

Aceptado: 03.06.2009.

* República 252, Santiago, Chile; gmedina@unab.cl a las drogas (eg. tuberculosis, Staphylococcus aureus, malaria), y que han irrumpido con epidemias locales (eg. ébola, hanta) o aquellos con escaso tratamiento o dificultad de ser prevenidos (eg. enfermedades de Hendra y Nipah) (Daszak y col 2001). Entre las enfermedades emergentes en especies silvestres se pueden identificar tres tipos: i) aquellas que se presentan debido a que la susceptibilidad del huésped se ha visto incrementada; ii) aquellas que debido a cambios ambientales, que favorecen al patógeno, se han tornado más virulentas; y iii) aquellas en que los patógenos recientemente han invadido nuevos huéspedes, con el sistema inmune debilitado, debido a situaciones ambientales adversas (Heide-Jorgensen y col 1992, Dobson y Foufopoulos 2001). La alta diversidad de potenciales huéspedes o reservorios para patógenos que existe en especies silvestres hace el estudio de la ecología de las enfermedades que afectan a estos animales particularmente difícil. Las enfermedades infecciosas en especies silvestres existen al interior de un paisaje identificado por factores climáticos, geográficos y ecológicos específicos. Es decir, poseen nidalidad, lo cual es la habilidad de mantener un foco dinámico y permanente de circulación del patógeno al interior de una comunidad y área geográfica determinada (Cabello y Cabello 2008). Por lo tanto, cualquier factor que tenga la capacidad de alterar la ecología del ecosistema que contenga el o los reservorios silvestres de la enfermedad tiene el potencial de alterar la nidalidad, modificando de esta manera su epidemiología (Tabor 2002). Por ejemplo, de 31 enfermedades estudiadas en especies silvestres y el hombre, 17 fueron facilitadas por 
actividades humanas. De éstas, la degradación del hábitat fue la principal causa en la aparición de las enfermedades (Dobson y Foufopoulos 2001).

Actualmente la realidad de los peligros para la conservación de la biodiversidad y el medio ambiente natural está convocando la integración de las disciplinas médicas y de historia natural, específicamente ecología y genética. Esta interdisciplinariedad se plantea dentro del nuevo campo llamado "Medicina de la Conservación", el cual se conforma por la combinación de varias disciplinas anteriormente separadas por tiempo y tradición (Tabor 2002). Por ejemplo, los problemas de conservación que enfrentan vertebrados acuáticos, al interior de una cuenca, son esencialmente multifactoriales, variando según la especie, la comunidad, el hábitat y la actividad humana a lo largo de una misma cuenca (Schwartz y col 2005). Entonces la Medicina de la Conservación plantea un enfoque integrando: a) cambios ambientales originados por el hombre; b) patógenos, parásitos y contaminantes; c) ecología y biodiversidad de especies silvestres, comunidades y el paisaje; y d) salud humana (Ostfeld y col 2002), es decir un enfoque transdisciplinario. Con el objetivo de ejemplificar la problemática de las enfermedades infecciosas en la conservación de especies silvestres, en esta revisión se discuten y documentan las variables ecológico-ambientales que están favoreciendo la emergencia de enfermedades infecciosas en especies silvestres, tales como el hábitat, contaminación, la introducción de especies alóctonas o exóticas y el cambio climático.

\section{EL HÁBITAT}

Los hábitats, sean éstos lagunas, lagos, ríos, pantanos, islas, praderas, suelos rocosos o bosques, se distribuyen $\mathrm{u}$ ordenan conformando un paisaje al interior de un área geográfica determinada. Dentro de este paisaje están también los hábitats intervenidos con elementos como praderas agrícolas, plantaciones forestales, villas, pueblos o ciudades, caminos, autopistas o trazados de ferrocarriles, conformando así lo que se llama una matriz, es decir, una estructura comparable con un tablero de ajedrez en donde cada cuadro es algún tipo de hábitat y la tabla el paisaje. Las poblaciones de organismos vivos se distribuyen en el paisaje dependiendo de la distribución de sus hábitats dentro de la matriz, ocupando los hábitats e interactuando con otros organismos en lo que se llama una comunidad. La biodiversidad de estas comunidades varía en el tiempo, entre otras cosas debido a modificaciones del hábitat tanto en su cantidad como calidad. En un paisaje determinado el hábitat puede estar fragmentado y estos fragmentos comunicados entre sí. Las poblaciones de una especie entonces se pueden distribuir en estos fragmentos en una estructura de metapoblación. Es decir, subpoblaciones, ocupando cada fragmento con distintos grados de aislamiento como resultado de la fragmentación, persistiendo un diferente grado de comunicación entre fragmentos, posibilitando de esta manera la migración de individuos entre los fragmentos (Fahrig 2003). Así en el caso que una de estas subpoblaciones se extinga, este fragmento tiene la posibilidad de ser recolonizado por individuos de otra subpoblación de manera que la metapoblación persiste en el tiempo. El proceso de fragmentación del hábitat en el tiempo posee tres componentes: i) reducción del tamaño de los fragmentos; ii) aumento de la distancia entre los fragmentos, y iii) aumento del efecto borde en los fragmentos. El aumento del efecto borde significa que la comunidad del fragmento es más susceptible a los efectos de la matriz circundante. Como resultado puede haber un cambio significativo en la estructura de la comunidad del fragmento (Pullin 2002).

La enfermedad de Lyme (Borrelia burgdorferi) en personas es transmitida en Centro y Norteamérica por una garrapata (Ixodes scapularis), siendo la prevalencia de las infectadas inversamente correlacionada con el área del fragmento. En fragmentos más pequeños la densidad del roedor huésped primario (Peromyscus leucopus), causante principal del contagio de la enfermedad en las personas, es mayor como resultado de la reducción de las poblaciones de competidores y depredadores (Nupp y Swihart 1998, Allan y col 2003). En este caso en la medida que los fragmentos de hábitat son mayores, la diversidad de la comunidad aumenta. Así en fragmentos de mayor tamaño que contienen una mayor diversidad de hábitat el incremento en la diversidad de especies huésped secundarias (menos importantes del contagio de la enfermedad en las personas) disminuye la posibilidad de infección de las garrapatas por el roedor huésped (efecto de dilución) y así el contagio de las personas (Ostfeld y Keesing 2000). Igualmente la prevalencia de parásitos gastrointestinales patógenos en el colobo rojo de Camerún (Pilicolobus tephrosceles) en Uganda se asocia con el grado de fragmentación y degradación del hábitat. Los individuos habitantes de aquellas áreas más degradadas presentaron un mayor riesgo de infección a nemátodos, aumentando la proporción de ejemplares con infecciones múltiples hacia los bordes de los fragmentos remanentes de hábitat. En Norteamérica la estructura del paisaje (fragmentación y conectividad) influye de manera importante en la distribución del virus hanta en su principal huésped, el roedor silvestre (Penomysens moniculatus); el roedor aumenta su dispersión entre fragmentos al acrecentarse la fragmentación, aumentando así la transmisión del virus (Langlois y col 2001). Estas observaciones sugieren que los patrones de infección registrados se relacionan con el mayor efecto antropogénico al ampliarse la fragmentación y variar la permeabilidad de la matriz (Gillespie y Chapman 2006). De manera más violenta, la eliminación repentina de un hábitat puede provocar la emigración de especies desde esa área y así de los patógenos asociados a éstas. La eliminación de los bosques debido a la construcción del aeropuerto internacional de Kuala Lumpur (Malasia) provocó la emigración de los murciélagos de la fruta a los 
árboles cercanos en centros agrícolas. Estos murciélagos reservorios naturales de paramixovirus tomaron contacto con cerdos domésticos, transmitiendo el virus y provocando la grave encefalitis conocida como enfermedad de Nipah (Weiss 2001). Estos antecedentes demuestran que la dinámica huésped-patógeno entre especies silvestres o entre especies silvestres y humanos puede ser gravemente afectada como resultado de la alteración, fragmentación o eliminación del hábitat. Por ejemplo, si un fragmento de hábitat que contiene una subpoblación de especie silvestre reservorio de un patógeno es conectado con otro fragmento con subpoblaciones de especies silvestres susceptibles al patógeno, mediante la implementación de corredores biológicos entre los fragmentos de hábitat como medidas de manejo para la conservación, esta medida originalmente creada para mejorar la situación de conservación puede terminar con la extinción de la subpoblación susceptible al patógeno (figura 1) (McCallum y Dobson 2002). Contrario a esta situación, cuando el huésped vector es de distribución amplia sobre el paisaje estudiado, el efecto sobre las poblaciones fragmentadas por comunicación de estas mediante corredores o translocación será mínimo (Cleaveland y col 2002). Al confrontar la teoría de metapoblaciones con la dinámica de los patógenos en un paisaje fragmentado, se puede apreciar que existe una correlación entre los términos de la teoría y la dinámica: a) fragmento de hábitat corresponde a una subpoblación de huéspedes; b) fragmentos desocupados: huéspedes susceptibles; c) fragmentos ocupados: huéspedes infectados; d) colonización: infección; e) extinción: muerte yf) migración: transmisión (Hess y col 2002). Variaciones inusuales de las densidades poblacionales también pueden afectar la ecología de los patógenos al aumentar el contacto entre individuos o aumentar el intercambio de individuos entre poblaciones antes separadas. Entre los años 1990 y 1992 un morbillivirus (Paramyxoviridae) eliminó miles de delfines (Stenella coeruleoalba) adultos en el Mar Mediterráneo. Al ser sólo adultos los que presentaron anticuerpos sugiere que la enfermedad no era endémica y que los delfines estaban perdiendo su inmunidad, por lo que existía un riesgo de nuevas epizootias. La información fue corroborada por estudios poblacionales en la región, los cuales mostraron

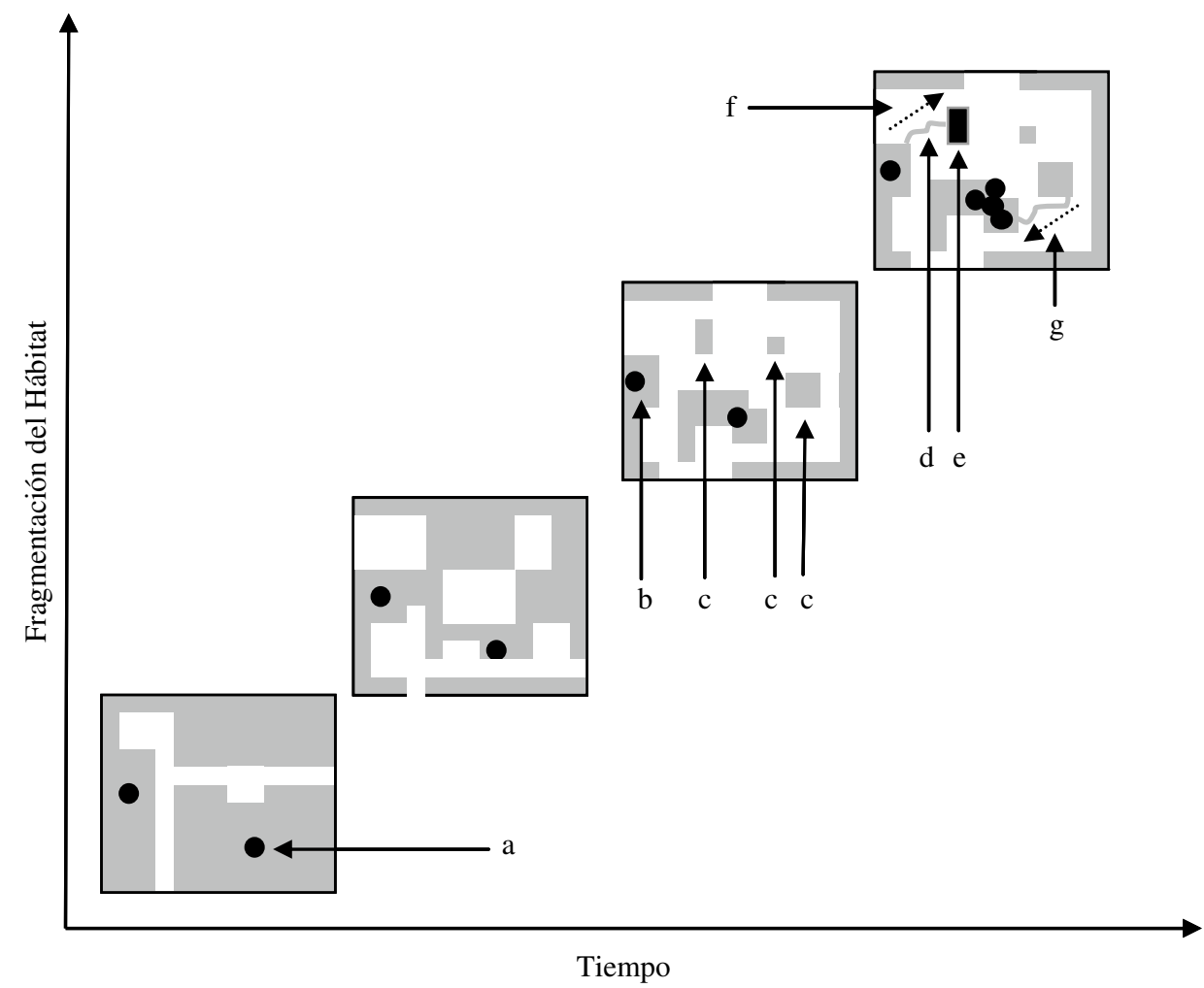

Figura 1. Efecto de la fragmentación del hábitat sobre la epidemiología de un patógeno (a) en una especie huésped dada distribuida en subpoblaciones como resultado de la fragmentación del hábitat (en gris). El patógeno se transmite desde los fragmentos con subpoblaciones de huéspedes infectadas (b) a fragmentos con subpoblaciones de huéspedes susceptibles (c), debido a la implementación de corredores biológicos o translocación (d), resultando en la extinción de la subpoblación susceptible (e) la dirección de la emigración de huéspedes infectados corresponde a (f) y la dirección de la recolonización o translocación con huéspedes susceptibles a (g).

Effect of habitat fragmentation on the epidemiology of a pathogen on a host (a) as an outcome of the pathogen transmission from occupied patches (b) to patches with susceptible hosts (c), due to the implementation of biological corridors (d), resulting in the extinction of the susceptible subpopulation (e). The direction of emigration of infected hosts is indicated as (f) and the direction of recolonization with susceptible hosts as (g). Habitat patches are shown in grey. 
densidades de delfines inusualmente altas. La enfermedad volvió a presentarse en el año 2007 (Raga y col 2008). Morbillivirus han sido descritos también en otros delfines (Tursiops truncatus) en el Atlántico y Golfo de México y en focas (Phoca vitulina) en el norte de Europa (Hall y col 1992, Duignan y col 1996). Otros virus de las familias Poxiviridae, Papoviridae, Herpesviridae, Orthomyxoviridae, Rhabdoviridae y Caliciviridae se han diagnosticado en cetáceos, mencionándose como elementos favorecedores de las infecciones la actividad pesquera, la pérdida de hábitat y la contaminación, pudiendo estos virus afectar sólo a un individuo o a la población completa (Van Bressem y col 1999).

\section{LA CONTAMINACIÓN}

Un importante elemento en la degradación del hábitat es la contaminación, ya que ésta puede facilitar la aparición de enfermedades en organismos marinos o terrestres. Es decir, una combinación de vulnerabilidad especie específica y la posibilidad de exposición al químico o tóxico por contacto directo o envenenamiento secundario. Por ejemplo, los químicos más comúnmente encontrados en especies silvestres terrestres son los herbicidas, los inhibidores de la colinesterasa y los rodenticidas anticoagulantes (Berny 2007). La utilización de pesticidas ha aumentado dramáticamente en los últimos 50 años para mejorar la producción agrícola; sólo en Europa se tienen inventariadas 100.000 sustancias químicas (European Inventory of New and Existing Chemical Substances, EINECS). El uso masivo de herbicidas (organofosforados, carbamatos) en el delta del Ebro (NE de España) es considerada la principal causa de la pérdida de la vegetación macrofítica en los 80 repercutiendo de esta manera en la desaparición de muchas especies de aves acuáticas (Mañosa y col 2001). Incluso la acumulación de municiones de plomo es asociada a la mortalidad de alrededor de 13.600 aves en el delta del Ebro (Mañosa y col 2001). El dramático caso de la casi extinción del cóndor de California (Gymnogyps californiatus) por contaminación por municiones de plomo ha provocado que hasta hoy en día sea muy difícil su reintroducción en los estados de Arizona y California (Cade 2007). En India la población del buitre bengalí (Gyps bengalensis) y el buitre picofino (Gyps indicus) disminuyó en más de un $95 \%$ desde 1990. La disminución fue inicialmente asociada a problemas renales e intestinales; sin embargo, investigaciones posteriores demostraron que esta catastrófica mortandad se debió a una contaminación de las aves por diclofenaco, un antiinflamatorio provocante del malfuncionamiento renal (Oaks y col 2004). Los efectos deletéreos de contaminantes sobre las células y los aspectos humorales del sistema inmune de mamíferos y peces son reconocidos (Arkoosh y Kaattari 1987, Rice y Weeks 1989, Dean y col 1990). Los organoclorados, por ejemplo, poseen propiedades tóxicas para el sistema inmune afectando la respuesta de las células $T$, contribuyendo a que el huésped se enferme o convierta en reservorio (Harvell y col 1999). En otro sentido, muchos contaminantes ambientales como metales pesados y radiaciones son reconocidos tóxicos a nivel cromosómico (Tapio y col 2006). Aves (Parus major y Ficedula hypoleuca) que han estado expuestas a metales pesados como arsénico o radiactividad han mostrado una mayor diversidad nucleotídica sugiriendo una mayor tasa de mutación en ambientes contaminados (Tapio y col 2006). Sin embargo, la ocurrencia de epidemias asociadas a contaminación en especies silvestres es una materia de riesgo y ha sido difícil de probar (Heide-Jorgensen y col 1992). Se ha sugerido que la contaminación por bifenilos policlorados (BPCs-PCBs) facilitó la epidemia del distemper en focas del Atlántico Norte en 1988/1989 al aumentar la susceptibilidad de la foca común (Phoca vitulina) (Hall y col 1992, Heide-Jorgensen y col 1992). En este caso se habría presentado una situación de contagio con un nuevo patógeno por una población en situación de susceptibilidad como resultado de la contaminación y el nuevo contacto con el principal huésped del patógeno, la foca de Groenlandia (Pagophilus groenlandicus), la cual habría modificado su distribución ocupando regiones al sur como resultado de la explotación de los recursos pesqueros del Ártico (Goodhard 1988). Esta migración y contagio provocó la muerte de cientos de focas comunes; esta susceptibilidad, al parecer, fue debida a la contaminación (Heide-Jorgensen y col 1992, Hall y col 2006).

En el caso de contaminantes asociados a actividades antropogénicas cercanas al litoral marino y de cursos de agua, estos contaminantes tienden a acumularse en el sedimento de los estuarios, los cuales actúan como depósitos. La exposición de vertebrados e invertebrados a estos contaminantes acumulados como hidrocarbonos clorinados y aromáticos, que son tóxicos inmunosupresores, ha aumentando las incidencias de enfermedades en peces juveniles (Arkoosh y col 1998). Esta degradación del hábitat aumenta el riesgo de epizootias por mayor susceptibilidad de individuos y poblaciones a los patógenos, lo que puede dejar a los sobrevivientes susceptibles de extinguirse por eventos ambientales y demográficos estocásticos (figura 2) (Arkoosh y col 1998, Cleaveland y col 2002, Harvell y col 2002). Por lo tanto, para la determinación del efecto de la contaminación en el surgimiento de enfermedades los modelos deben incorporar variables ambientales como temperatura y sobreexplotación de recursos, pues ambos influyen en la ecología de las especies (Hall y col 2006).

\section{LAS ESPECIES ALÓCTONAS}

Las especies alóctonas, es decir, especies introducidas por el hombre y de origen distinto a la región en donde se introdujeron, son un importante elemento asociado al surgimiento de enfermedades infecciosas en especies silvestres. Los patógenos emergentes pueden ser nativos, exóticos o posiblemente exóticos. Nativo es aquel que ha coexistido por largo tiempo en la población huésped; 


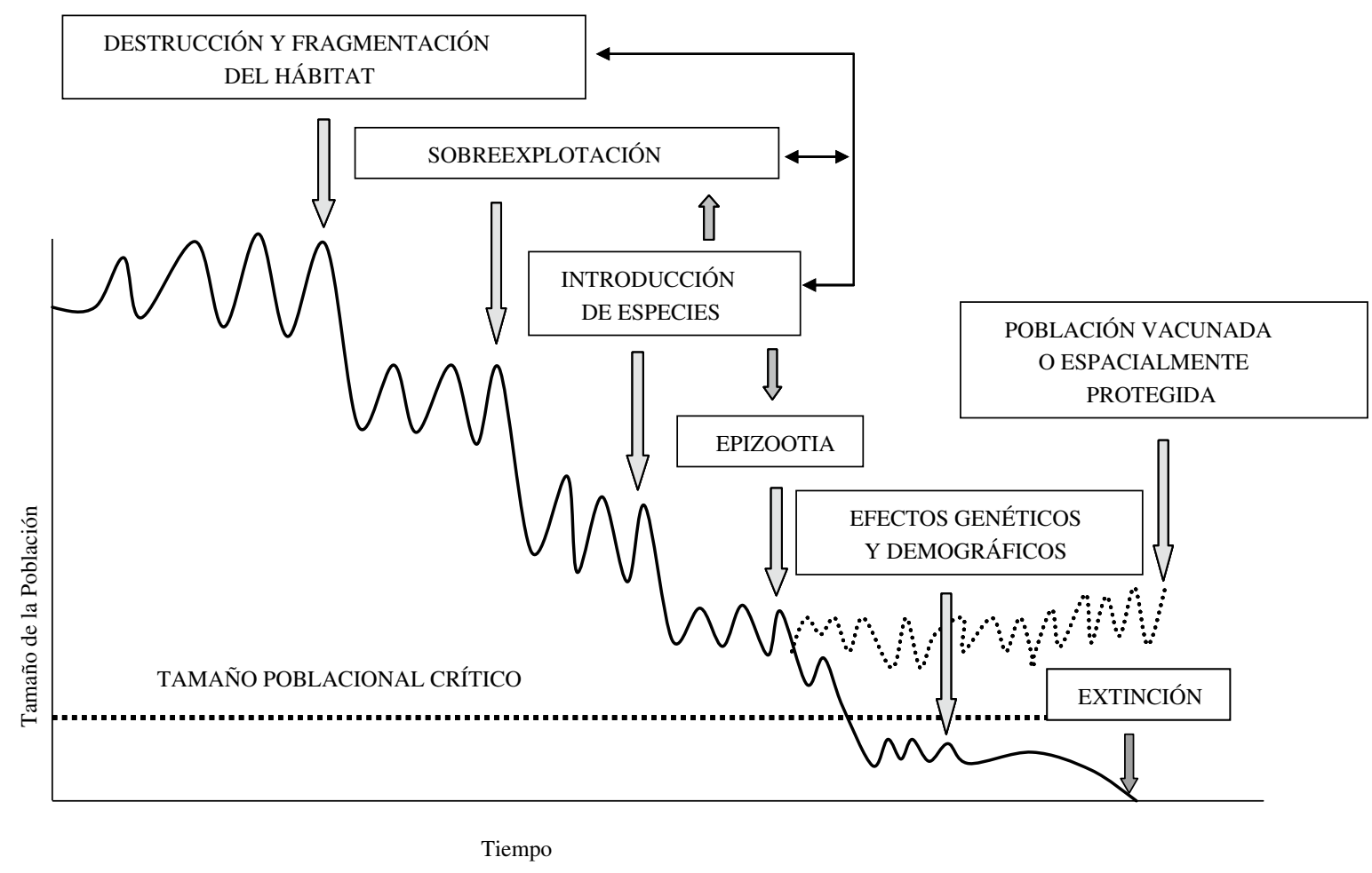

Figura 2. Efecto de una enfermedad infecciosa emergente sobre una población dada como resultado de condiciones ambientales y poblacionales del huésped favorables al patógeno.

Effect of a emerging infectious disease on a population under favorable environmental and host population conditions.

exótico es aquel originado en una región geográfica diferente o en una población diferente, pero en la misma región; y posiblemente exótico son aquellos de los cuales no se sabe su origen pero sí se tiene información circunstancial que son patógenos asociados a especies alóctonas $\mathrm{o}$ asociadas a actividades antropogénicas que indican un origen no nativo (Dobson y Foufopoulos 2001). El hongo quítrico Batrachochytrium dendrobatidis posee el típico ciclo de vida de las enfermedades emergentes exóticas. Tiene un rango amplio y la capacidad de reproducirse rápidamente en poblaciones de anfibios susceptibles, sobrevive saprofíticamente en el suelo o en las partes queratínicas de larvas mejorando la persistencia del patógeno y evitando así la recuperación de las poblaciones infectadas. La quitridiomicosis ha sido identificada como la causa de la muerte en masa, disminución poblacional y extinción de especies de anfibios (e.g. Rheobatrachus spp., Bufo periglenes) en todo el mundo (Daszak y col 1999). Esta pandemia está asociada al comercio internacional de anfibios, introducción de anfibios alóctonos en ambientes naturales o la contaminación con esporas de sistemas de agua dulce por medio de desagües (Daszak y col 2003, Fisher y Garner 2007). Igualmente la rabia, enfermedad cada vez más distribuida en el mundo, fue introducida en las poblaciones silvestres de mapaches (Procyon lotor) en los estados al sur de Nueva York (Estados Unidos) mediante la liberación en la región de mapaches infectados traídos desde otras regiones (Dobson 2000).

Un caso particularmente complejo son los centros de rescate y reproducción en cautiverio de especies silvestres. En estos casos especies silvestres son concentradas en espacios reducidos, lo cual favorece la transmisión de enfermedades con el riesgo de infectar las poblaciones residentes y receptoras de los animales liberados. Esta situación es más común en especies carismáticas como carnívoros, aves rapaces y ungulados. En el programa de reintroducción del hurón de patas negras (Mustela nigripes) en Wyoming, Estados Unidos, seis hurones capturados para el programa de cría en cautiverio poseían parvovirus, la población manejada desapareció totalmente producto de la enfermedad y el programa se vio retrasado en varios años (Thorne y Williams 1988). Al interactuar especies domésticas exóticas y silvestres se favorece el contagio de enfermedades (Dobson y Foufopoulos 2001). En África la población de perros domésticos que deambulan libremente se caracteriza por una alta tasa de crecimiento alterando la ecología de varias enfermedades infecciosas como rabia y distemper canino, lo cual ha afectado a varias especies de felinos y caninos silvestres en varias regiones de África (Cleaveland y col 2002). La malaria aviar introducida en Hawai a través de aves alóctonas eliminó completamente la avifauna de la mayoría de los bosques bajo los 
1.200 m.s.n.m. (Van Riper III y col 1986). En California, Estados Unidos, un estudio multidisciplinario para conocer la ecología del parvovirus canino y calicivirus felino en el zorro gris (Urocyon cinereargenteus) y el lince rojo (Lynx rufus) demostró que zorros cercanos a perros domésticos fueron significativamente más seropositivos a parvovirus canino que aquellos zorros más alejados. Igualmente el mayor número de linces positivos a calicivirus felino fue correlacionado con la presencia de gatos domésticos (Riley y col 2004). En este caso, la combinación del estudio del comportamiento espacial de los animales silvestres y domésticos y la información de los patógenos permitieron una mejor comprensión del problema. Del mismo modo, con la aplicación de la filogenia se ha podido determinar la población de origen de donde provino el contagio de las especies silvestres (Roelke-Parker y col 1996).

En el sur de España se evaluó la presencia de parásitos helmintos dañinos en crías de lince ibérico (Lynx pardinus). Se analizaron cinco linces, 19 gatos domésticos asilvestrados (Felis catus), 12 mangostas (Herpestes ichneumon) y cuatro jinetas (Genetta genetta). El parásito Ancylostoma tubaeforme fue encontrado en el $80 \%$ de los gatos domésticos al igual que Toxocara cati (31\%), Jayeuxiella pasquali (21\%), Mesocestoides sp. (5\%). Estos parásitos fueron encontrados en sólo un lince de los analizados (20\%). De las otras especies de carnívoros solamente en una mangosta se presentó parasitismo con helmintos no encontrados en el lince. Así, el gato doméstico puede ser un importante reservorio de parásitos dañinos para la sobrevivencia del lince (Millán y Casanova 2007). Similar es el caso con enfermedades infecciosas como leucemia felina, parvovirus y aneovirus-1 caninos, Ehrlichia spp., patógenos como Mycobacterium bovis, Leptospira interrogans y Cytauzoon spp. Estas enfermedades y bacterias fueron identificadas en el lince, al mismo tiempo que una prevalencia de $4,5 \%$ al $11,4 \%$ en gatos domésticos, entre $32 \%$ al $42 \%$ en perros y entre el $12 \%$ y $30 \%$ en zorros (Millán y col 2009). La escasa vacunación de perros en las regiones habitadas por el lince y la baja inmunidad del lince a estas enfermedades infecciosas dejan a la población de esta especie susceptible de ser afectada por una epidemia producto de la distribución simpátrica con los gatos y perros, pudiendo el zorro convertirse en el vector silvestre (Millán y col 2009).

Además del perro y gato doméstico, la introducción de otras especies con fines comerciales, control biológico o científico ha provocado la emergencia de enfermedades infecciosas en nuevas regiones. Se han descrito nuevos ciclos de enfermedades debido a la introducción de especies alóctonas. Por ejemplo el gato doméstico, el armiño (Mustela erminea) y el hurón (Mustela furo) en Nueva Zelanda, y el visón (Mustela vison) en Europa (Ragg y col 1995, Mañas y col 2001). En especies acuáticas los cultivos de peces están ejerciendo un importante rol en el ciclo de vida de patógenos al proteger los peces juveniles de los parásitos asociados a los huéspedes adultos y al concentrar grandes poblaciones de peces en reducidas áreas geográficas, o al escapar especies alóctonas de los cultivos. Un caso es el parásito Lepeophtheirus salmones, el cual ha retardado la edad de contagio de salmones juveniles de vida silvestre (Krkošek y col 2006). Similar es el caso de la difilobotriasis en Chile. El cultivo del salmón ha tenido la habilidad de expandir la distribución del parásito Diphyllobothrium latum desde las regiones IX y X a otras regiones de Chile y casos clínicos en humanos han sido diagnosticados en Brasil (Cabello 2007).

Las especies alóctonas se pueden sumar a los factores ambientales anteriormente expuestos afectando las poblaciones silvestres. En este caso, la pérdida de individuos de la población por una epizootia puede ser la diferencia entre sobrevivencia y extinción, al acelerar la declinación poblacional bajo el nivel demográfico crítico (figura 2).

Una importante causa del ingreso de especies alóctonas es el comercio internacional. La pandemia humana por el vibrión parahemolítico en Chile y en el mundo por la cepa O3:K6 probablemente ha sido el resultado del aumento del transporte marítimo y sus millones de litros de agua de mar transportados en los estanques de lastre de los buques, asociado esto al cambio climático y la expansión de la acuicultura de moluscos filtradores (Cabello y col 2007). Sólo en Estados Unidos se estima que los volúmenes de aguas transportadas en los estanques de lastre superan los 79 millones de toneladas anuales (Drake y col 2002), y la abundancia promedio de bacterias acarreadas se estimó en $8,3 \times 10^{8}$ y 7,4 x 109 de partículas virales en la Bahía de Chesapeak (Ruiz y col 2000). De forma similar, la epidemia del virus de influenza H5N1 en 1998 provino de la disposición artificial de patos y pollos en los mercados de Hong Kong (Weiss 2001). El ébola, virus de la fiebre de Marburg, por primera vez se identificó asociado a un grupo de monos cercopitecos verdes (Cercopithecus aethiops) de Uganda destinados a laboratorios en Alemania y la ex Yugoslavia en 1967. A los pocos días este virus contagió al personal encargado de remover los desechos reportándose un 23\% de letalidad (Ledermann 2003). También se puede dar el caso con especies migratorias; por ejemplo, aves provenientes de África contagiaron a aves residentes de Nueva York y mosquitos del género Culex, los cuales actuaron como vectores contagiando a personas con la fiebre del Nilo en 1999 (Rappole y col 2000, Weiss 2001). Por lo tanto, la evaluación del riesgo de enfermedades infecciosas emergentes en especies silvestres en un paisaje dado debe enfocarse en patógenos que pueden causar altas mortalidades, que permanecen por más tiempo en el medio silvestre y que además pueden causar disminuciones poblacionales al afectar las tasas de fecundidad y reclutamiento (Cleaveland y col 2002). El manejo o rescate de poblaciones silvestres en riesgo podría enfocarse en la erradicación de la enfermedad mediante la vacunación de las especies reservorios. Sin embargo, esto es difícil ya que generalmente se conoce poco de la ecología del reservorio y de la epidemiología de 
la enfermedad en los ambientes naturales. De esta forma la intensidad y cobertura del programa de vacunación son desconocidas. Por ejemplo, si las tasas de nacimiento de perros y gatos domésticos asilvestrados o vagabundos son altas, estas poblaciones necesitarán de una alta frecuencia de vacunación. Igualmente, si la prevención de enfermedades en perros y gatos resulta en un aumento del bienestar y sobrevivencia de individuos, esto puede significar un aumento de la población reservorio de otras patologías (Cleaveland y col 2002). Por otra parte, la vacunación de un número reducido de individuos de una especie silvestre (20\%-40\%) puede ser suficiente para proteger la población de caídas a densidades con graves riesgos de extinción. Esto responde de manera similar al aislamiento de un número determinado de individuos para protegerlos de otros huéspedes vectores (figura 2) (Cleaveland y col 2002). Es importante recordar que si la especie huésped alóctona posee una alta capacidad invasora y el patógeno es generalista, el potencial de contagio de especies nativas susceptibles será alto, justificando la creación de refugios o medidas de vacunación preventivas. Por último, no se debe descartar que el diagnosticar a una especie silvestre con problemas de conservación, como reservorio de un patógeno de importancia económica, puede resultar en la intención pública de eliminar la especie.

\section{EL CAMBIO CLIMÁTICO}

Muchos aspectos del cambio climático y su efecto en sistemas biológicos son particularmente importantes. El calentamiento está ocurriendo desproporcionadamente en regiones de mayores latitudes o altitudes. Como respuesta, ciertas especies de estas regiones se desplazarán a nuevas latitudes y altitudes favoreciendo el contacto con nuevos vectores y huéspedes (Levins y col 1994). Muchos vectores de enfermedades infecciosas están limitados por las temperaturas ambientales, por ejemplo la malaria aviar introducida en la isla de Hawai se limita a los 1.200 m.s.n.m. Esta distribución de la enfermedad se debe al ambiente más templado existente bajo esta altitud, la cual favorece a los mosquitos vectores de la enfermedad. Al igual que otras enfermedades virales, bacterianas o parasitarias en donde sus vectores poseen limitaciones de temperatura ambiental para su distribución, un aumento de las temperaturas ambientales puede significar la desaparición o un aumento de la distribución de éstos (Harvell y col 2002).

Entender la relación entre las enfermedades y el clima es difícil debido a la naturaleza multivariada del cambio climático y la escasamente probada relación entre epizootias y cambio climático, es decir, aún no se ha descrito la relación absoluta causa-efecto entre clima y enfermedades (Harvell y col 2002). Sin embargo, además del surgimiento de enfermedades infecciosas en un gran número de taxones existen otros síntomas biológicos que pueden estar relacionados con el cambio climático global; éstos incluyen declinación de anfibios, polinizadores y la proliferación de algas dañinas en ecosistemas marinos (Epstein 2002). En la península Antártica la temperatura aumentó en más de $2,5^{\circ} \mathrm{C}$ el siglo pasado, y nuevos datos demuestran una significativa disminución de los hielos árticos (Krabill y col 1999). Sin embargo, en esta región se han presentado varios casos en donde aún se requiere entender si la emergencia de enfermedades se debe a: i) una mejor condición ambiental (aumento de la temperatura); ii) una mayor presencia humana; o iii) una combinación de las dos anteriores. Patógenos como Salmonella spp., Campylobacter jejuni, Helicobacter spp. han sido descritos en aves y mamíferos antárticos (Broman y col 2000, Palmgren y col 2000, Oxley y McKay 2005). El cólera aviar (Pasteurella multocida) se ha descrito en skuas (Catharaca lonnbergu) y pingüinos de penacho amarillo (Eudyptes chrysocome) (Parmelee 1978, Trivelpiece y col 1981, de Lisle y col 1990). Recientemente la bacteria del tipo Campylobacter spp. fue aislada de leones marinos (Phacarctos hookeri) (Gales y Childerhouse 1999). Nemátodos (Stretocora spp., Cyclophyllida spp) y cestodos (Cyclophyllida spp, Tetrabothrium spp) fueron aislados de estómagos e intestinos de pingüinos papúas en la isla Ardley, Shetland del Sur (Fredes y col 2006). Análisis serológicos de muestras de sangre realizadas en las islas Subantárticas (South Georgia) indicaron que el virus de la influenza aviar A está presente en pingüinos papúas (Pygoscelis papua), sin embargo, el virus aún no ha sido aislado en aves de la Antártica (Wallensten y col 2006). El aumento de la distribución mundial del cólera aviar es probablemente la causa más importante en la disminución del albatros de pico fino (Diomedea chloroohynchos) en la isla Amsterdam $\left(37^{\circ} \mathrm{S}, 70^{\circ} \mathrm{E}\right)$, que previamente había sido atribuido a la pesquería. Esta patología probablemente también ha afectado al albatros oscuro (Phoebetria fusca) y el albatros de Amsterdam (D. amsterdamensis) (Weimerskirch 2004).

Los cambios climáticos inducen cambios en el medio ambiente afectando la productividad de los ecosistemas. En el caso de los ecosistemas marinos estos cambios ambientales se extienden en escalas temporales y espaciales (Harvell y col 1999). Se ha reportado un dramático aumento de nuevas patologías antes no descritas en coincidencia con el incremento de las temperaturas asociadas al aumento de la intensidad del fenómeno oceánico El Niño (ENSO en sus siglas en inglés). Entre 1938 y 1997, 34 casos de eventos de mortalidad masiva de especies en los mares fueron documentados: algas (5 spp.), corales (spp), esponja (1 spp.), moluscos (3 spp.), peces (3 spp.), focas (4 spp.), marsopa (1 spp.) y delfín (1 spp.) (Harvell y col 1999, Harvell y col 2002, House y col 2002). Otras bacterias como Cytophaga psychrophila se evidencian en peces por exposiciones anormales a bajas temperaturas $\left(4{ }^{\circ} \mathrm{C}-10{ }^{\circ} \mathrm{C}\right)$ (Holt y col 1989). La expansión del parasitismo en ostras (Crassostrea virginica) por Perkinsus marinus en la costa este de Estados Unidos y el Golfo de México ha sido asociada a la oscilación del fenómeno El 
Niño (Powell y col 1996, Dekshenieks y col 2000). Los arrecifes de coral pierden las algas simbióticas provocándose extensas mortalidades en los corales y el surgimiento de infecciones como las causantes por la bacteria Vibrio silio e infecciones micóticas. Estos cambios ambientales y climáticos pueden causar estrés fisiológico, comprometer la resistencia inmunológica de los huéspedes y aumentar la frecuencia de enfermedades infecciosas.

Una compleja situación es la provocada por las explosiones demográficas de algas, lo que se conoce por marea roja. Producto de la explosión demográfica de algas en extensas regiones marinas, cetáceos, pinnípedos, peces, moluscos y seres humanos han sido afectados por las toxinas de estas algas. Más de 85 tóxicos han sido descritos en estos dinoflagelados. Al exponer algas experimentalmente a un aumento de $4{ }^{\circ} \mathrm{C}$ en el ambiente (aumento de la temperatura de los mares proyectada hacia el 2100) las especies Skeletonema costatum (diatomea) y Rhodomonas sp. (Crisoficeae) no variaron sus tasas de crecimiento, mientras que dos especies tóxicas, Phaeocystis globosa (Prymnesiophyta) y Pseudo-nitzschia multiseries (diatomea) murieron rápidamente en dichas condiciones de temperatura marina proyectadas para el 2100. Sin embargo, las otras algas tóxicas estudiadas, los dinoflagelados Prorocentrum micans y Prorocentrum minimum (Dinoficeas) y Fibrocapsa japonica (Raphidophyceae) junto con Chattonella antiqua (Raphidophyceae) doblaron sus tasas de crecimiento poblacional (Peperzak 2003). Estos resultados sugieren que producto del aumento de las temperaturas oceánicas como resultado del cambio climático en conjunto con la degradación ambiental por contaminación y sobreexplotación de recursos, aumentará el riesgo de eventos demográficos de algas tóxicas en los océanos con el consiguiente efecto sobre la biodiversidad marina, la industria pesquera y la salud humana (Peperzak 2003).

Durante 1980 la disminución drástica del erizo (Diadema antillarum) en el Caribe contribuyó al cambio del ecosistema marino desde uno dominado por el equinodermo a otro dominado por algas. La secuencia de mortalidad de los erizos coincidió con las corrientes marinas de superficie, sin embargo los casos no asociados sugirieron la existencia de un patógeno acuático como causa de las mortalidades (Lessios y col 1984). Aunque ya se llevan décadas en investigaciones sobre los agentes biológicos que estructuran las comunidades marinas naturales, el impacto ecológico y evolutivo de las enfermedades infecciosas es en su mayoría poco conocido y controversial, lo que complica aún más la comprensión del efecto del cambio climático (Harvell y col 1999).

\section{LA SITUACIÓN DE CHILE}

Frente a los antecedentes expuestos de otras regiones del planeta, en Chile podría darse un aumento de la casuística de enfermedades infecciosas en especies silvestres como consecuencia de la alteración de los hábitats, el aumento del contacto con humanos, animales domésticos y especies alóctonas, y condiciones ambientales favorables derivadas de la contaminación y el cambio climático. Algunos antecedentes que respaldan esta visión son, por ejemplo, el caso del virus del síndrome pulmonar por hantavirus, el que se diagnosticó por primera vez en el suroeste de Norteamérica durante la explosión poblacional de un roedor (Peromyscus). Posteriormente se diagnosticaron casos similares en la Patagonia asociados a roedores silvestres, encontrándose el virus "variedad Andes" en Chile, del cual el principal reservorio es el roedor silvestre Oligoryzomys longicaudatus (Torres-Pérez y col 2004, Ortiz y col 2004). Recientemente un ejemplar de Rattus rattus (especie introducida en Chile) capturado en la localidad de Naque, Los Vilos, resultó positivo a la variedad Andes de hantavirus (Lobos y col 2005). Sin embargo, se han verificado casos de la enfermedad en Argentina y Chile en los años 1959, 1975 y 1985, sugiriéndose que la enfermedad sería tan antigua como los roedores que la hospedan (Murúa y col 2003). En esta enfermedad el conjunto de factores como el cambio climático, cambios en la biodiversidad (disminución de los depredadores, invasión por especies exóticas), comportamiento de las personas (invasión humana de ecosistemas, aumento de los desechos domiciliarios, viviendas deficientes) han resultado en cambios demográficos de O. longicaudatus y un aumento de la casuística en humanos (Murúa y col 2003, Lobos y col 2005). Sin embargo, estudios realizados en Canadá con el roedor Penomysens moniculatus, reservorio principal del virus hanta, sugieren que aspectos como el comportamiento de dispersión del roedor favorecido por la fragmentación del hábitat y la disposición de estos fragmentos en el paisaje, serían los elementos más influyentes en los patrones de distribución del virus en las poblaciones del roedor (Langlois y col 2001). Otro antecedente es el caso de las garrapatas, las cuales son importantes vectores de patógenos, sumado a las dermatitis y pérdidas sanguíneas que a su vez pueden provocar debilitamientos del sistema inmune del huésped. En aves de corral la garrapata (Argas miniatus) transmite la borreliosis (Borrelia anserina) y la bacteria Aegyptianella pullorum (egipcianelosis) en polluelos de pingüinos de Humboldt (Spheniscus humboldti) (Hoogstraal 1985). En el caso de las garrapatas se identifican a) endémicas o establecidas (13 especies); b) probablemente establecidas o endémicas (5 especies); c) dudosamente establecidas (5 especies); d) exóticas (3 especies); e) erróneamente identificadas como presentes en Chile (7 especies); y f) especies con un estatus incierto (8 especies) (González-Acuña y Guglielmone 2005). También se describen 22 familias y 34 géneros de helmintos en aves silvestres de los géneros Charadriiformes y Pelecaniformes (Hinojosa-Sáez y González-Acuña 2005). En el caso que el cambio climático y la explotación forestal resulten en una disminución de la humedad en el centro-sur y sur del país, puede afectarse la distribución de las vinchucas (Triatoma infestans y Mepraia spinolai o 
Triatoma spinolai), ambos vectores de Trypanosoma cruzi causante de la enfermedad zoonótica de Chagas en niños. Esta situación puede verse agravada por la existencia de un tercer potencial vector también silvestre, Mepraia gajardoi, habitante aparentemente limitado al desierto costero entre los $18^{\circ} \mathrm{S}$ y $26^{\circ} \mathrm{S}$, el cual podría desplazarse a regiones más al sur como resultado del aumento de las temperaturas y aridez ambiental (Canales y col 2000, Cabello y Cabello 2008). Los artrópodos son vectores para un número importante de zoonosis emergentes con reservorio silvestre, como ocurre con las garrapatas del género Ixodes (Borrelia, enfermedad de Lyme), Anaplasma, Ehrlichia y el virus de la encefalitis, moscas del tipo Glossina, insectos del tipo Triatoma y Reduvidae son importantes como vectores de tripanosomas (Cabello y Cabello 2008).

En todas las regiones rurales, litoral marino y ribera de ríos y lagos en Chile existen asentamientos humanos de diferente tamaño que mantienen poblaciones de perros y gatos que deambulan libremente por calles, caminos y bosques; la depredación e interacción de perros con especies silvestres en Chile ha sido previamente documentada (Simeone y Bernal 2000, Medina-Vogel y col 2007). Debido a estas interacciones directas existe una alta probabilidad de transmisión de enfermedades infecciosas virales, bacterianas o parasitarias (Butler y col 2004). Por ejemplo, la nutria de río de Norteamérica ha sido testeada como seropositiva a parvovirus canino (Kimber y Kollias 2000). Parvovirus del visón (Mustela vison), carnívoro introducido en Chile, Argentina y Europa, es cercano al virus de la panleucopenia felina y el parvovirus canino (Parrish y col 1982). Igualmente el distemper en mustélidos es causado por el virus del distemper canino (Hammer y col 2007). Adenovirus Tipo 1 canino se ha identificado en nutrias de río, pudiendo éste ser transmitido desde perro, gatos, hurones o visones (Park y col 2007). En Chile existen cuatro especies y cuatro subespecies pertenecientes a la familia Mustelidae, además de tres especies de zorros (Canidae) y cinco especies de gatos silvestres (Felidae), todos potenciales huéspedes de estas patologías (Quintana y col 2000). Estas patologías comprometen el sistema inmune y en el caso de los mustélidos predisponen a infecciones secundarias por Pneumocystis carinii y Toxoplasma gondii (Dyer y Schamber 1999, Frank 2001). Un estudio en la cuenca del río Maullín (X Región) determinó un 73,3\% de visones $(\mathrm{N}=30)$ seropositivos a Toxoplasma gondii, existiendo una asociación positiva con los asentamientos humanos (Sepúlveda 2008). Del total de 113 sueros obtenidos de llamas (Lama glama) y 127 de alpacas (Lama pacos) de criaderos de las V y IX regiones, en $43 \%$ de las llamas y $12 \%$ de las alpacas se encontraron anticuerpos a T. gondii (Patitucci y col 2006). También se ha descrito una amplia distribución de la leptospirosis en Chile actuando como reservorios los roedores silvestres e introducidos (Rattus rattus, $R$. norvegicus, Mus musculus), bovinos, cerdos y perros, con diferencias en la prevalencia entre regiones debido a variaciones en la humedad ambiental
(Zamora y Riedemann 1999). En la provincia de Valdivia se ha identificado leptospira en roedores de zonas rurales ( $41 \%$ ) y urbanas (24\%), siendo la prevalencia en roedores introducidos de un 26\% del total de roedores capturados (Zamora y Riedemann 1999). Igualmente se han encontrado altos porcentajes de presencia de anticuerpos contra serovar pomona en alpacas chilenas (Hill y Wyeth 1991). Se sospecha que la presencia de anticuerpos en zorros (Pseudalopex culpaeus y P. griseus) se pueda deber a que los roedores son parte de la dieta de éstos (Zamora y Riedemann 1999). Es decir, de acuerdo con los antecedentes de este capítulo y los anteriores, las especies silvestres chilenas no están exentas de riesgo de ser significativamente afectadas por enfermedades infecciosas emergentes (cuadro 1). Una importancia no menor adquieren las aves endémicas y restringidas a islas o islotes a lo largo de la costa de Chile o islas oceánicas. Las aves endémicas de islas son especialmente susceptibles al ingreso de nuevos patógenos (Wikelski y col 2004). De acuerdo a Schlatter y Simeone (1999) al menos 19 especies de aves marinas nidifican en islas e islotes oceánicos, sin que se acerquen jamás a tierra firme: Procellariidae (6 spp.), Oceanitidae (2 spp.), Phaethontidae (2 spp.), Sulidae (3 spp.), Fregatidae (1 sp.), Laridae (5 spp.). Además, en el archipiélago de Juan Fernández existen tres especies de aves terrestres endémicas (Sephanoides fernandensis, Anairetes fernandezianus, Aphrastura masafuerae) con complejos estados de conservación.

En el país los programas de conservación de especies o comunidades están escasamente equipados para poder reaccionar al surgimiento de epidemias en especies silvestres, especialmente debido a una grave falta de personal de campo, la no existencia de controles periódicos de enfermedades en especies silvestres o tóxicos ambientales en los ecosistemas, la no existencia de una política de control de especies domésticas (perros, gatos) que deambulan libremente en ambientes silvestres, y por último, dificultades en la integración multisectorial y por lo tanto multidisciplinaria para enfrentar situaciones de conservación del paisaje, comunidades y especies animales (Medina-Vogel 2005). Tampoco las enfermedades de importancia en conservación de la biodiversidad han tenido relevancia en los programas de conservación. De hecho, la bibliografía relacionada con conservación de la biodiversidad y el medio ambiente escasamente menciona el problema. Por ejemplo, el Informe País, Estado del Ambiente en Chile-1999 (Universidad de Chile, Centro de Análisis de Políticas Públicas 2000); Globalización y Biodiversidad. Oportunidades y desafíos para la sociedad chilena (Editorial Universitaria, Santiago, Chile, 2003); Biodiversidad Marina: Valoración, Usos y Perspectivas ¿Hacia dónde va Chile? (Editorial Universitaria, Santiago, Chile, 2005); Biodiversidad en Ambientes Fragmentados de Chile: patrones y procesos a diferentes escalas (Editorial Universitaria, Santiago, Chile, 2006). Y muy escaso en libros como: Fundamentos de Conservación Biológica; 
Cuadro 1. Enfermedades infecciosas en mamíferos chilenos y posibles reservorios. Infectious diseases in Chilean mammals and potential reservoirs.

\begin{tabular}{llll}
\hline Huésped en riesgo & \multicolumn{1}{c}{ Patógeno } & Reservorios alóctonos & Reservorios domésticos \\
\hline Zorros, murciélago. & $\begin{array}{l}\text { Rabia, distemper canino, } \\
\text { leptospirosis. }\end{array}$ & Ratas, conejo, liebre. & $\begin{array}{l}\text { Perros, gatos, ganado } \\
\text { bovino, porcino, perros. }\end{array}$ \\
$\begin{array}{l}\text { Lobo marino, huemul, taruca, pudú, coipo, } \\
\text { roedores silvestres: }\end{array}$ & Leptospirosis. & $\begin{array}{l}\text { Jabalí, ciervos, ratas, } \\
\text { conejo, liebres. }\end{array}$ & $\begin{array}{l}\text { Ganado bovino, porcino, } \\
\text { perros. }\end{array}$ \\
$\begin{array}{l}\text { Huemul, taruca, pudú, camélidos } \\
\text { sudamericanos, quique, huroncito }\end{array}$ & $\begin{array}{l}\text { Brucelosis, tuberculosis } \\
\text { bovina, toxoplasmosis. }\end{array}$ & Jabalí, ciervos, visón. & Ganado bovino, porcino. \\
$\begin{array}{l}\text { Lobos marinos, huillín, chungungo, quique, } \\
\text { huroncito, chingues, armadillo }\end{array}$ & $\begin{array}{l}\text { Distemper canino. } \\
\text { Distemper canino, parvovirus } \\
\text { canino y felino, influenza } \\
\text { felina, leptospirosis, } \\
\text { adenovirus canino. }\end{array}$ & Visón. & $\begin{array}{l}\text { Perros. } \\
\text { Perros, gatos, hurones. }\end{array}$ \\
Puma, gatos silvestres, huillín, chungungo & $\begin{array}{l}\text { Toxoplasmosis. } \\
\text { Cetáceos }\end{array}$ & $\begin{array}{l}\text { Morbilivirus, papilomavirus, } \\
\text { herpesvirus. }\end{array}$ & Otros cetáceos. \\
\hline
\end{tabular}

Lobo marino (Otaria byronia), huemul (Hippocamelus bisulcus), taruca (Hipocamelus antisensis) pudú (Pudu pudu), coipo (Mycastor coypus), camelidos (Lama guanicoe, L. glama, L. pacos, Vicugna vicugna), quique (Galictis cuja), huronsito (Lycodon patagonicus), huillin (Lontra provocax), chungungo (Lontra felina), chingues (Conepatus chinga ), ciervos (Cervus elaphus, Dama dama, Capreolus capreolus), visón (Mustela vison), ratas (Rattus rattus, Rattus norvegicus), zorros (Pseudalopex griseus, P. culpeus, P. fluvipes), gatos silvestres (Puma concolor, Lynchailurus colocolo, Oncifelis geoffroyi, O. guigna, Oreailurus jacobitus), armadillo(Chaetophractus spp.), conejo (Oryctolagus cuniculus) liebre (Lepus capensis), murciélago (Amorphochilus schnabili).

Perspectivas Latinoamericanas (Fondo de Cultura Económica México. DF., México, 2001); Cría en Cautividad de Fauna Chilena (Seminario Internacional sobre Cría en Cautiverio, Santiago 2001); Historia, biodiversidad y ecología de los bosques costeros de Chile (Editorial Universitaria, Santiago, Chile 2005). En el caso del Plan Para La Conservación del Huemul del Sur (Hippocamelus bisulcus) de la Corporación Nacional Forestal (CONAF) y el Comité Pro Defensa de la Fauna y Flora (CODEFF) (2001), se plantea la necesidad de comenzar un proyecto orientado a la prospección de la diversidad de parásitos y enfermedades relacionadas con el huemul y otras especies huéspedes como el ganado bovino y los ciervos introducidos. Esta actividad se plantea en conjunto a otras como corredores, reintroducción y traslado de ejemplares desde diferentes regiones, pero sin especificar prioridad temporal en estas iniciativas. Sin embargo, el Servicio Agrícola y Ganadero (SAG) en aduanas, límites fronterizos, áreas rurales y ciudades mantiene vigilancia epidemiológica en animales domésticos y silvestres ${ }^{1}$. Muchas iniciativas pueden realizarse para recopilar evidencias concretas de los riesgos de las enfermedades infecciosas para las especies silvestres chilenas, algunas pueden ser la experimentación científica rigurosa para determinar cuáles enfermedades infecciosas presentan un peligro a especies silvestres con problemas de conservación; la combinación de datos o información existente con la teoría para estimar las circunstancias propicias que puedan causar epizootias en especies silvestres con problemas de conservación; y por último el fortalecimiento de la vigilancia epidemiológica junto al estudio de la ecología de enfermedades infecciosas que incluya especies silvestres nativas, alóctonas y domésticas.

\section{CONCLUSIONES}

En las últimas décadas ha habido un aumento del diagnóstico de enfermedades infecciosas en especies silvestres. Al poseer las enfermedades infecciosas en especies silvestres nidalidad, cualquier elemento que altere la ecología del ecosistema tiene el potencial de alterar la ecología de la enfermedad.

De acuerdo con los antecedentes expuestos en este trabajo, las causas identificadas como disruptores de la ecología de un paisaje o región y facilitadoras de enfermedades infecciosas emergentes en especies silvestres pueden agruparse en: 1) alteraciones físicas o químicas al hábitat; 2) sobreexplotación; 3) interacciones con especies alóctonas depredadoras o competidoras; 4) interacciones con nuevos huéspedes vectores; y 5) migraciones a nuevos hábitat o regiones. Estas cinco causas pueden además ser potenciadas por el cambio climático.

La introducción de especies es un aspecto muy importante en la ecología de las enfermedades infecciosas en especies silvestres, en particular debido a que estas nuevas especies pueden actuar como nuevos huéspedes 
o reservorios de los patógenos y favorecer la transmisión entre especies, especialmente entre especies domésticas y silvestres al haber especies alóctonas que sobreponen su distribución con especies domésticas y silvestres. Igualmente los centros de rescate de especies silvestres deben tener especial cuidado en el control de patógenos, pues pueden favorecer la diseminación de éstos a nuevas poblaciones, o la infección de otras especies de otras regiones.

Al ser multicausal la emergencia de enfermedades infecciosas en especies silvestres, el nuevo campo de la Medicina de la Conservación plantea la transdisciplina como el enfoque para enfrentar los casos en un ecosistema y paisaje dado. Es decir, la dificultad de erradicar reservorios silvestres hace que el manejo de las poblaciones deba orientarse hacia la salud del ecosistema. Esto significa el trabajo coordinado entre disciplinas como restauración ecológica, ecotoxicología, genética de la conservación, epidemiología, ecología de poblaciones, el paisaje, salud y educación pública. Medidas aisladas, no coordinadas pueden resultar en efectos no deseados. Por ejemplo, la eliminación de una especie por efectos secundarios de los pesticidas puede resultar en un aumento poblacional de especies consideradas plagas (Hone 1994). Dentro de este contexto, el término "Salud de Ecosistema" debe entenderse como un concepto de manejo adaptativo más que evaluación de la situación biológica de un ecosistema en un momento y espacio dados. En otras palabras, es el estudio continuo para mitigar o eliminar los factores ambientales limitantes, entendiéndose como factores limitantes aquellos elementos químicos, físicos o biológicos que una vez agregados o restados del medio afectan significativamente la salud de las especies, las poblaciones o la comunidad (Pantus y Dennison 2005).

La distribución de las poblaciones de una especie en particular en el paisaje y su aislamiento, como las características del patógeno, son importantes de conocer antes de realizar manejos que incluyan la comunicación de poblaciones antes aisladas entre sí. Patógenos generalistas pueden rápidamente diezmar una población que ha estado separada del patógeno por razones geográficas. Patógenos con reducidos períodos de virulencia probablemente persistirán en grandes poblaciones altamente comunicadas; en cambio, será escaso en poblaciones pequeñas fragmentadas. Igualmente la diversidad de hábitats dentro de los cuales se encuentra una comunidad de especies puede tener gran influencia en la ecología de enfermedades infecciosas. Así como los patógenos especialistas causantes de altas mortalidades no pueden persistir en pequeñas poblaciones aisladas, los patógenos generalistas presentan los principales riesgos al poder sobrevivir en una variedad de hábitats y diferentes especies huéspedes.

Los efectos de alteraciones al medio ambiente, introducción de competidores o depredadores, pueden reducir la población afectada a un nivel que finalmente los factores demográficos o ambientales estocásticos pueden causar la extinción de la especie. Este aspecto es de gran importancia en conservación de especies silvestres pues en el caso de no conocerse la existencia de patógenos en huéspedes de la población fuente, la susceptibilidad de la población receptora, o la situación sanitaria de los individuos trasladados entre diferentes regiones, o de otros huéspedes habitantes de la matriz asociada a los fragmentos a comunicar o el corredor biológico a implementar, la pérdida de individuos de la población por una epizootia, pueden hacer la diferencia entre sobrevivencia y extinción al acelerar la reducción poblacional bajo el nivel demográfico crítico. Entonces, el aislar y caracterizar en el paisaje el o los patógenos, junto con la determinación de la distribución de las poblaciones en un paisaje, su demografía, interacciones interespecíficas y posibles rutas de migración y recolonización entre fragmentos del hábitat, se pueden desarrollar planes de conservación y manejo adelantados a las posibles epizootias, vacunar un número determinado de individuos, aislar algunas subpoblaciones de los vectores o controlar vectores. Paralelamente se pueden estudiar los eventos históricos de las poblaciones y su capacidad actual para enfrentar eventos demográficos o ambientales estocásticos.

Tomando en cuenta esta realidad existe una urgente necesidad del desarrollo de estudios multidisciplinarios sobre el efecto de enfermedades infecciosas en la Salud de Ecosistemas dentro de la compleja situación de las especies exóticas invasoras, la alteración y destrucción de los hábitats, la movilización de la población humana y especies domésticas hacia ecosistemas antes no poblados, el aumento exponencial del comercio y transporte internacional y la contaminación global de los ecosistemas terrestres y acuáticos. Sin embargo, la investigación no podrá por sí misma solucionar los problemas de conservación. Si los gobernantes y personas afectadas perciben la investigación en conservación y prevención como irrelevante y autosuficiente, o si los investigadores fracasan en comunicar adecuadamente a las autoridades o personas afectadas en posiciones de decisión, el conocimiento obtenido por las investigaciones será ignorado y no se podrá lograr una solución efectiva. Por lo tanto dentro del enfoque multidisciplinario deben incluirse importantes programas de capacitación y formación de profesionales con conocimiento de la transdisciplinariedad en Medicina de la Conservación. Médicos veterinarios pueden rápidamente capacitarse en estudios de posgrado en áreas de conservación in situ o ex situ, en evaluación de la salud de especies silvestres y especies domésticas en regiones agrícolas, monitoreando especialmente aquellas especies vectores o reservorios de los patógenos, trabajar en el desarrollo de nuevas técnicas de diagnóstico, y en investigación de las relaciones interespecíficas y los efectos de las modificaciones al ambiente producidas por las actividades humanas, participando en las decisiones sobre explotación de especies silvestres o la introducción de nuevas especies.

Finalmente se puede concluir que los reportes de enfermedades en especies silvestres están en aumento. Las 
enfermedades están afectando especies de invertebrados, vertebrados tanto acuáticos como terrestres, sin o con importante efecto en las economías y sistemas productivos asociados a comunidades humanas. Lo más grave, varias enfermedades pueden estar afectando especies poco conocidas, las cuales pueden estar desapareciendo sin ser notadas.

\section{RESUMEN}

Las recientes publicaciones científicas respecto de enfermedades infecciosas emergentes en especies silvestres están aumentando la preocupación internacional en el deterioro de la salud del ecosistema de los océanos, ambientes terrestres y límnicos. Se estudiaron investigaciones publicadas en los últimos 25 años. Los objetivos de este estudio fueron: 1) determinar la importancia del hábitat y la introducción de especies alóctonas, dentro del contexto de la contaminación y el cambio climático, en el surgimiento de enfermedades infecciosas, y 2) evaluar el riesgo de extinción de especies con problemas de conservación. La evaluación de los casos escogidos, más importantes, permite concluir que los patógenos responsables de las enfermedades infecciosas en especies silvestres pueden transmitirse rápidamente entre huéspedes pudiendo llegar a producir en corto tiempo epizootias que pueden poner en peligro poblaciones vulnerables en declinación. La destrucción del hábitat y la introducción de especies alóctonas son variables ambientales que significativamente afectan la ecología de las enfermedades infecciosas emergentes. En cambio la contaminación y el cambio climático actúan como variables ambientales que favorecen la transmisión y la creación de nuevos huéspedes. Esta multicausalidad en el origen de las enfermedades genera la necesidad de un enfoque transdisciplinario para enfrentarlas. El riesgo creciente de epizootias debido a las variables ambientales y biológicas estudiadas, fuerza incluir en los planes de conservación y rescate de especies silvestres la ecología de las enfermedades infecciosas.

\section{AGRADECIMIENTOS}

El autor expresa sus agradecimientos a los profesores Juliana de Abreu Vianna, Dr. Carlos González y Dr. Alejandro Simeone por importantes comentarios al manuscrito. Este trabajo es parte de las actividades de investigación del proyecto interno DI-01-06/R de la Dirección de Investigación y Doctorados de la Universidad Andrés Bello.

\section{REFERENCIAS}

Allan BF, F Keesing, RS Ostfeld. 2003. Effect of forest fragmentation on Lyme disease risk. Conserv Biol 17, 267-272.

Arkoosh MR, SL Kaattari. 1987. Effect of early aflatoxin B1 exposure on in vivo and in vitro antibody responses in rainbow trout, Salmo gairdneri. J Fish Biol A 31, 19-22.

Arkoosh MR, E Casillas, E Clemons, AN Kagley, R Olson, P Reno, JE Stein. 1998. Effect of pollution on fish diseases: potential impacts on salmonid populations. J Aquat Anim Health 10, 182-190.

Berny P. 2007. Pesticides and the intoxication of wild animals. J Vert Pharmacol Therap 30, 93-100.

Butler JRA, JT Toit, J Bingham. 2004. Free-ranging domestic dogs (Canis familiaris) as predators and prey in rural Zimbabwe: threats of competition and disease to large wild carnivores. Biol Conserv 115, 369-378.

Broman T, SLW Bergstron, H Palmgren, DJ McCafferty, M Sellin, B Olsen. 2000. Isolation and characterization of Campylobacter jejuni subsp. jejuni from macaroni penguins (Eudyptes chrysolophus) in the subantarctic region. Appl Environ Microb 66, 449-452.

Cabello FC. 2007. Acuicultura y salud pública. La expansión de la difilobotriasis en Chile y el mundo. Rev Med Chile 135, 10641071.
Cabello FC, RT Espejo, MC Hernández, ML Rioseco, J Ulloa, JA Vergara. 2007. Vibrio parahaemolyticus O3:K6 epidemic diarrhea, Chile, 2005, Emerg Infect Dis 13, 655-656.

Cabello C, F Cabello. 2008. Zoonosis con reservorios silvestres: amenazas a la salud pública y a la economía. Rev Méd Chile 136, 385-393.

Cade TJ. 2007. Exposure of California condor to lead from spent ammunition. $J$ Wildlife Manage 71, 2125-2133.

Canales M, M Ehrenfeld, PE Cattan. 2000. Situación de Mepraia spinolai, vector silvestre de la enfermedad de Chagas en Chile, en relación con otros vectores desde la perspectiva de sus fuentes de alimentación. Rev Méd Chile 128, 1108-1112.

Chapman CA, ML Speirs, TR Gillespie, T Holland, KM Austad. 2006. Life on the edge: gastrointestinal parasites from the forest edge and interior primate groups. Am J Primatol 68, 397-409.

Cleaveland S, GR Hess, AP Dobson, MK Laurenson, HI McCallum, MG Roberts, R Woodroffe. 2002. The role of pathogens in biological conservation. In: Hudson PJ (ed). The Ecology of Wildlife Diseases. Oxford University Press, New York, USA, Pp 139-150.

Daszak P, L Berger, AA Cunningham, AD Hyatt, DE Green, R Speare. 1999. Emerging infectious diseases and amphibian population declines. Emerg Infect Dis 5, 735-748.

Daszak P, AA Cunningham, AD Hyatt. 2000. Emerging infectious diseases of wildlife-threats to biodiversity and human health. Science 287, 443-449.

Daszak P, AA Cunningham, AD Hyatt. 2001. Anthropogenic environmental change and the emergence of infectious diseases in wildlife. Acta Trop 78, 103-116.

Daszak P, AA Cunningham. 2002. Emerging Infectious Diseases. A key role for Conservation Medicine In: Aguirre AA, Ostfeld RS, Tabor GM, Pearl MC (eds). Conservation Medicine. Ecological Health in Practice. Oxford University Press, New York, USA, Pp 40-61.

Daszak P, AA Cunningham, AD Hyatt. 2003. Infectious disease and amphibian population declines. Divers Distrb 9, 141-150.

Dean JH, JB Cornacoff, MI Luster. 1990. Toxicity to the immune system. Immunol Rev 1, 377-408.

Dekshenieks MM, EE Hofmann, EN Powell. 2000. Quantifying the effect of environmental change on an oyster population: a modelling study. Estuaries 23, 593-610.

Dobson A. 2000. Racoon rabies in space and time. Proc Natl Acad Sci USA 97, 14041-14063.

Dobson A, J Foufopoulos. 2001. Emerging infectious pathogens of wildlife. Phil Trans R Soc Lond B 356, 1001-1012.

Drake LA, GM Ruiz, BS Galil, TL Mullady, DO Friedmann, FC Dobbs. 2002. Microbial ecology of ballast water during a transoceanic voyage and the effect of open-ocean exchange. Mar Ecol-Prog Ser 233, 13-20.

Duignan PJ, C House, DK Odell, RS Wells, LJ Hansen, MT Walsh, DJ St Aubin, BK Rima, JR Geraci. 1996. Morbillivirus infection in bottlenose dolphins: evidence for recurrent epizootics in the western Atlantic and Gulf of Mexico. Mr Mammal Sci 12, 499-515.

Dyer NW, GJ Schamber. 1999. Pneumocystosis associated with canine distemper virus infection in a mink. Can Vet $J$ 40, 577-578.

Epstein PR. 2002. Biodiversity, Climate Change, and Emerging Infectious Diseases. In: Aguirre AA, Ostfeld RS, Tabor GM, Pearl MC (eds). Conservation Medicine. Ecological Health in Practice. Oxford University Press, New York, USA, Pp 27-39.

Fahrig L. 2003. Effects of habitat fragmentation on biodiversity. Аnпи Rev Ecol Evol 34, 487-515.

Fisher MC, TWJ Garner. 2007. The relationship between the emergence of Batrachochytrium dendrobatidis, the international trade in amphibians and introduced amphibian species. Fungal Biol Rev 21, 2-9.

Frank RK. 2001. An outbreak of toxoplasmosis in farmed mink (Mustela vison S.) J Vet Diagn Invest 13, 245-249.

Fredes F, E Raffo, P Muñoz, M Herrera. 2006. Fauna parasitaria gastrointestinal en polluelos de Pingüino Papúa (Pygoscelis papúa) encontrados muertos en zona antártica especialmente protegida (KZAEP N $\left.{ }^{\circ} 150\right)$. Parsitol Latinoam 61, 179-182. 
Gales N, S Childerhouse. 1999. Field observations and sampling regime. In: Baker A (ed). Unusual Mortality of the New Zealand sea lion, Phocarctos hookeri, Auckland Islands, January-February 1998. Department of Conservation, Wellington, New Zealand, Pp 8-19.

Gillespie TR, CA Chapman. 2006. Prediction of parasite infection dynamics in primate metapopulation based attributes of forest fragmentation. Conserv Biol 20, 441-448.

González-Acuña D, AA Guglielmone 2005. Ticks (Acari: Argasidae, ixodidae) of Chile. Exp Appl Acarol 35, 147-163.

Goodhard CB. 1988. Did virus transfer from harp seals to common seals? Nature 336, 21.

Hall AJ, PP Pomeroy, J Harwood. 1992. The descriptive epizootiology of phocine distemper in the UK during 1988/89. Sci Total Environ $115,31-44$.

Hall AJ, PD Jepson, SJ Goodman, T Härkönen. 2006. Phocine distemper virus in the north and European seas-data and models, nature and nature. Biol Conserv 131, 221-229.

Hammer AS, HH Dietz, S Hamilton-Dutoit. 2007. Immunohistochemical detection of 3 viral infections in paraffin-embedded tissue from mink (Mustela vison): a tissue-microarray-based study. Can J Vet Res 71, 8-13.

Harvell CD, K Kim, JM Burkholder, RR Colwell, PR Epstein, DJ Grimes, EE Hofmann, EK Lipp, ADME Osterhaus, RM Overstreet, JW Porter, GW Smith, GR Vasta. 1999. Emerging marine diseases-Climate link and anthropogenic factors. Science 285, 1505-1510.

Harvell CD, CE Mitchell, JR Ward, S Altizer, AP Dobson, RS Ostfeld, MD Samuel. 2002. Climate warming and disease risks for terrestrial and marine biota. Science 296, 2158-2162.

Haydon DT, MK Laurenson, C Sillero-Zubiri. 2002. Integrating epidemiology into population viability analysis: managing the risk posed by rabies and canine distemper to the Ethiopian wolf. Conserv Biol 16, 1372-1385.

Heide-Jorgensen MP, T Harkonen, R Dietz, PM Thompson. 1992. Retrospective of the 1988 European seal epizootic. Dis Aquat Organisms 13, 37-62.

Hess GR, SE Randolph, P Arneberg, C Chemini, C Furlanello, J Harwood, MG Roberts, J Swinton. 2002. Spatial aspects of disease dynamics. In: Hudson PJ (ed). The Ecology of Wildlife Diseases, Oxford University Press, New York, USA, Pp 102-118.

Hill FI, TK Wyeth. 1991. Serological reaction against Leptospira interrogans serovar in alpacas alter vaccination. $N$ Zealand Vet $J$ 39, 32-33.

Hinojosa-Sáez A, D González-Acuña. 2005. Estado actual del conocimiento de helmintos en aves silvestres de Chile. Gayana 69, 241-253.

Holt RA, A Amandi, JS Rohovec, JL Fryer. 1989. Relation of water temperature to bacterial cold-water disease in coho salmon, chinook salmon, and rainbow trout. J Aquat Anim Health 1, 94-101.

Hone J. 1994. Analysis of vertebrate pest control. Cambridge University Press, Cambridge, UK.

Hoogstraal HY, CWsef, J Hays, Keirans. 1985. Ornithodoros (Alectorobius) spheniscus n. sp. (Acarina: Ixodoidea: Argasidae: Ornitodoros (Alectorobius) capensis group), a ticks parasite of the Humboldt penguin in Perú. J Parasitol 7, 635-644.

House C, AA Aguirre, JA House. 2002. Emergence of Infectious Diseases in Marine Mammals. In: Aguirre AA, Ostfeld RS, Tabor GM, Pearl MC (eds). Conservation Medicine. Ecological Health in Practice. Oxford University Press, New York, USA, Pp 104-117.

Johannessen OM, Shalina EV, MW Miles. 1999. Satellite evidence for an Arctic Sea ice cover in transformation. Science 86, 1937-1939.

Kimber KR, GV Kollias. 2000. Infectious and Parasitic Diseases and Contaminant-Related Problems Of North American River Otters (Lontra Canadensis): A Review. J Zoo Wild Med 31, 452-472.

Krabill W, E Frederick, S Manizade, C Martin, J Sonntag, R Swift, R Thomas, W Wright, J Yungel. 1999. Rapid thinning of parts of the southern Greenland ice. Sheet. Science 283, 1522-1524.

Krkošek M, MA Lewis, A Morton, LN Frazer, JP Volpe. 2006. Epizootics of wild fish induced by farm fish. PNAS 103, 15506-15510.
Langlois JP, L Fahrig, G Merriam, H Artsob. 2001. Landscape structure influences continental distribution of hantavirus in deer mice. Lanscape Ecol 16, 255-266.

Lisle GWD, WL Stanislawek, PJ Moors. 1990. Pasteurella multocida infection in Rockhopper Penguins (Eudyptes chrysocome) form Campbell Island, New Zealand. J Wildlife Dis 26, 283-285.

Ledermann WD. 2003. Ébola: corta y reciente historia de un joven virus. Rev Chil Infect 2003, 113-114.

Lessios HA, DR Robertson, JD Cubit.1984. Spred of Diadema mass mortality through the Caribbean. Science 226, 335-337.

Levins R, T Auerbach, U Brinkmann. 1994. The emergence of new diseases. Am Sci 82, 52-60.

Lobos G, M Ferres, RE Palma. 2005. Presencia de los géneros invasores Mus y Rattus en áreas naturales de Chile: un riesgo ambiental y epidemiológico. Rev Chilena de Hist Nat 78, 113-124.

Mañas S, JC Ceña, J Ruiz-Olmo, S Palazón, M Domingo, J Wolfinbarger, $\mathrm{M}$ Bloom. 2001. Aleutian mink disease parvovirus in wild riparian carnivores in Spain. $J$ Wildlife Dis 37, 138-144.

Mañosa S, R Mateo, R Guitart. 2001. A review of the effects of agricultural and industrial contamination on the Ebro delta biota and wildlife. Environ Monit Assess 71, 187-205.

Medina-Vogel G. 2005. Estrategia regional para la conservación del huillín (contra provocax) en Chile. En Smith-Ramírez C, Armesto JJ, Valdovinos C (eds). Historia, Biodiversidad y Ecología de los Bosques Costeros de Chile. Editorial Universitaria, Santiago, Chile, Pp 505-515.

Medina-Vogel G, F Boher, G Flores, A Santibáñez, C Soto-Azat C. 2007. Spacing behavior of Marine otters (Lontra felina) in relation to land refuges and fishery wastes in Central Chile. J Mammal 88, 487-494.

McCallum H, A Dobson. 2002. Disease, habitat fragmentation and conservation. Prc R Soc Lond 269, 2041-2049.

Millán L, JC Casanova. 2007. Helminth parasites of the endangered Iberian lynx (Lynx pardinus) and sympatric carnivores. J Helminthol $81,377-380$

Millán J, MG Candela, F Palomares, MJ Cubero, A Rodríguez, M Barral, J Fuente, S Almería, L León-Vizcaíno. 2009. Disease threats to the endangered Iberian lynx (Lynx pardinus). Vet J, 182, 114-124.

Murúa R, M Navarrete, R Cádiz, R Figueroa, P Padula, L Zaror, R Mansilla, L González, A Muñoz-Pedreros. 2003. Síndrome pulmonar por Hantavirus: situación de los roedores reservorios y la población humana en la Décima Región, Chile. Rev Méd Chile 131, 169-176.

Nupp TE, RK Swihart. 1998. Effect of forest fragmentation on population attributes of white-footed mice and eastern chipmunks. J Mammal 79, 1234-1243.

Oaks, JL, M Gilbert, MZ Virani, RT Watson, CU Meteyer, BA Rideout, HL Shivaprasad, S Ahmed, MJI Chaudhry, M Arshad, S Mahmood, A Ali, AA Khan. 2004. Diclofenac residues as the cause of vulture population decline in Pakistan. Nature 427, 630-633.

Ortiz JC, Venegas W, Sandoval JA, Chandía P, F Torres-Pérez. 2004. Hantavirus en roedores de la Octava Región de Chile. Rev Chil Hist Nat 77, 251-256.

Ostfeld RS, F Keesing. 2000. Biodiversity and disease risk: the case of Lyme disease. Conserv Biol 14, 722-728.

Ostfeld RS, GK Meffe, MC Perl. 2002. Conservation Medicine. The birth of Another Crisis Discipline. In: Aguirre AA, Ostfeld RS, Tabor GM, Pearl MC (eds). Conservation Medicine. Ecological Health in Practice. Oxford University Press, New York, USA, Pp 17-26.

Oxley APA, DB McKay 2005. Comparison of Helicobacter spp. genetic sequences in wild and captive seals, and gulls. Dis Aquat Org 65, 99-105.

Pantus FJ, WC Dennison. 2005. Quantifying and Evaluating Ecosystem Health: A Case Study from Morton Bay, Australia. Env Mang 36, 1-15

Palmgren H, D McCafferty, A Aspán, T Broman, M Sellin, R Wollin, S Bergström, B Olsen. 2000. Salmonella in sub-Antarctica: low 
heterogeneity in salmonella serotypes in South Georgian seals and birds. Epidemiol Infect 125, 257-262.

Park NY, MC Lee, NV Kurkure, HS Cho. 2007. Canine Adenovirus Type 1 Infection of Eurasian River Otter (Lutra lutra). Vet Pathol 44, 536-539.

Parkinson CL, DJ Cavalieri, P Gloersen, HJ Zwally, JC Comiso. 1999. Spatial distribution of trends and seasonality in the hemispheric sea ice covers. J Geophys Res 104, 20827-20835.

Parmelee DF, SJ Maxson, NP Bernstein 1978. Fowl cholera outbreak among brown skuas at palmer Station. Antarct J Unit States 14, 168-169.

Parrish CR, LE Carmichael, DF Antczak. 1982. Antigenic relationships between canine parvovirus type 2 , feline panleukopenia virus and mink enteritis virus using conventional antisera and monoclonal antibodies. Arch Virol 72, 267-278.

Patitucci AN, MJ Pérez, G Barril, CM Cárcamo, A Muñoz. 2006. Detección de anticuerpos séricos contra Toxoplasma gondii (Nicolle y Maceaux, 1909) en llamas (Lama glama Linneaus, 1758) y alpacas (Lama pacos Linneaus, 1758) de Chile. Arch Med Vet 38, 179-182.

Peperzak L. 2003. Climate change and harmful algal blooms in the North Seal. Acta Oecol 24, 139-144.

Powell EN, JM Klinck, EE Hofmann. 1996. Modeling diseased oyster population II. Triggering mechanisms for Perkinsus marinus. J Shellfish Res 15, 141-165.

Pullin AS. 2002. Conservation Biology. Cambridge University Press, Cambridge, UK.

Quintana V, J Yáñez, M Valdebenito. 2000. Orden carnívora. En: Muñoz A, Yáñez J (eds). Mamíferos de Chile. CEA Ediciones, Valdivia, Chile, Pp 155-187.

Raga JA, A Banyard, M Domingo, M Corteyn, MF Van Bressem, M Fernández, FJ Aznar, T Barrett. 2008. Dolphin morbillivirus epizootic resurgence, Mediterranean Sea. Emerg Inf Dis 14, 472-473.

Ragg JR, H Moller, KA Waldrup. 1995. The prevalence of bovine tuberculosis (Mycobacterium bovis) infections in feral population of cats (Felis catus), ferrets (Mustela furo) and stoats (Mustela erminea) in Otago, New Zealand. New Zeal Vet J 43, 333-337.

Rappole, JH, SR Derrickson, Z Hubalek. 2000. Migratory birds and spread of West Nile virus in the Western Hemisphere. Emerg Infect Dis 6, 319-328.

Rice CD, BA Weeks. 1989. Influence of tributyltin on in vitro activation of oyster toadfish macrophages. J Aquat Anim Health 1, 62-68.

Riley SPD, J Foley, B Chomel. 2004. Exposure to feline and canine pathogens in bobcats and gray foxes in urban and rural zones of a national park in California. $J$ Wildl Dis 40, 11-22.

Roelke-Parker ME, L Munson, C Packer, R Kock, S Cleveland, M Carpenter, SJ O’Brien, A Pospischil, R Hofmann-Lehmann, H Lutz, L George, M Mwamengele, MN Mgasa, GA Machange, BA Summers, MJG Appel. 1996. A canine distemper virus epidemic in Serengeti lions (Panthera leo). Nature 379, 441-445.

Rothrock DA, Y Yu, GA Marykut. 1999. Thinning of the Arctic Sea ice cover. J Geophys Res Lett 26, 3469-3472.
Ruiz GM, TK Rawlings, FC Dobbs, LA Drake, T Mullady, A Huq, RR Colwell. 2000. Global spread of microorganisms by ships. Nature 408, 49-50.

Schlatter R, A Simeone. 1999. Estado del conocimiento y conservación de las aves en mares chilenos. Estudios Oceanológicos 18, 25-33.

Schwartz J, B Aldridge, M Blanchard, FC Mohr, J Stott. 2005. The development of methods for immunophenotypic and lymphocyte function analyzes for assessment of Southern sea otter (Enhydra lutris nereis) health. Vet Immunol Immunop 104, 1-14.

Sepúlveda, M. 2008. Patógenos específicos del Visón Americano (Mustela vison) en la cuenca del río Maullín. Tesis de Magíster, Facultad de Ciencias Veterinarias, Universidad Austral de Chile, Valdivia, Chile.

Simeone A, M Bernal. 2000. Effects of habitat modification on breeding seabirds: a case study in central Chile. Waterbirds 23, 449-456.

Tabor GM. 2002. Defining Conservation Medicine. In: Aguirre AA, Ostfeld RS, Tabor GM, Pearl MC (eds). Conservation Medicine. Ecological Health in Practice. Oxford University Press, New York, USA, Pp 8-16.

Tapio E, B Eugen, K Boris. 2006. Environmental pollution affects genetic diversity in wild bird populations. Mutation research 608, 8-15.

Thorne ET, ES Williams. 1988. Disease and Endangered Species: The Black-footed Ferret as a Recent Example. Conserv Biol 2, 66-74,

Torres-Pérez F, J Navarrete-Droguett, R Aldunate, TL Yates, GL Mertz, PA Vial, M Ferres, PA Marquet, RE Palma. 2004. Peridomestic small mammals associated with confirmed cases of human hantavirus disease in southern Chile. Am J Trop Med Hyg 70, 305-309.

Trivelpiece W, RG Butler, N Volkman. 1981. Pygoscelid penguin research in Admiralty Bay. Antarct J Unit States 16, 150-152.

Van Bressem MF, K Van Waerebeek, JA Raga. 1999. A review of virus infections of cetaceans and the potential impact of morbilliviruses, poxviruses and papillomaviruses on host population dynamics. Dis Aquat Org 38, 53-65.

Van Riper III C SG Van Riper, ML Goff, M laird. 1986. The epizootiology and ecological significance of malaria in Hawaiian land birds. Ecol Monogr 56, 327-344.

Wallensten A, VJ Munster, ADME Osterhaus, J Waldenström, J Bonnedahl, T Broman, RAM Fouchier, B Olsen. 2006. Mounting evidence for the presence of influenza A virus in the avifauna of the Antarctic region. Antarct Sci 18, 353-356.

Weimerskirch H. 2004. Diseases threaten southern ocean albatrosses. Polar Biol 27, 374-379.

Weiss RA. 2001. The Leeuwenhoek Lecture 2001. Animal origins of human infectious disease. Phil Trans $R$ Soc Lond 356, 957-977.

Wikelski M, J Foufopoulos, H Vargas, H Snell. 2004. Galápagos birds and diseases: invasive pathogens as threat for island species. Ecol Soc 9, 5-14.

Zamora J, S Riedemann. 1999. Especies silvestres como reservorios de leptospirosis en Chile. Una revisión de los estudios efectuados en el país. Arch Med Vet 31, 151-156. 